\title{
An innocent heart murmur... not always so innocent!
}

\section{Un soplo cardíaco inocente... ¡no siempre tan inocente!}

Pierina P. Quiroz-Zegarra ${ }^{1 *}$, Gladys Espinoza-Rivas², Sara Munive-Rojas², and Cristian Aguilar-Carrañza ${ }^{3}$

${ }^{1}$ Cardiology Service, Universidad Nacional Mayor de San Marcos; ${ }^{2}$ Non-invasive Cardiology Service; ${ }^{3}$ Diagnostic and Treatment Support Service, Instituto Nacional Cardiovascular, Lima, Peru

A 30-year-old man with a history of innocent heart murmur diagnosed in childhood presented recurrent high fever that did not go away with antibiotics or self-administered antipyretic treatment. In addition, he developed the consumptive syndrome. Therefore, an echocardiography was performed, which showed the presence of a fistula between the right coronary aortic sinus of Valsalva and the right atria. Infective endocarditis was diagnosed and treated with intravenous Vancomycin-gentamicin, so the fever resolved. Then, he was transferred to our hospital to surgical treatment.

Laboratory test revealed a normal white blood cell count and negative blood cultures.

Transthoracic echocardiography showed right atria and left cavities enlarged due to chronic fistula with preserved left ventricular systolic function (Fig. 1A). Transesophageal echocardiography (TEE) demonstrated high flow fistulous tract $(8 \mathrm{~mm})$ between the right coronary aortic sinus of Valsalva and the right atria (adjacent septal tricuspid valve) with small hyperechogenic images that may correspond to vegetation (Fig. 1B-C; Video. S1-S2).
Surgery confirmed the echocardiographic findings, so surgical closure of the defect with a pericaridial patch was performed. Then, intra-operative TEE by color flow showed severe tricuspid regurgitationtand no residual fistula at the site of repair, so a tricuspid annuloplasty was performed. The patient was admitted to the intensive care unit, under antibiotic treatment, with favorable evolution. Hematoxylin and eosin staining showed vegetation constituted by fibrin with scarce chronic inflammatory infiltrate, multiple areas of dystrophic calcification, and multiple bacterial colonies (Fig. 1D). No acute inflammatory infiltrate was identified. A gram stain revealed colonies of Gram-positive bacteria (Fig. 1E).

\section{Conflicts of interest}

None.

\section{Funding}

None.

\section{Correspondence:}

Date of reception: 06-05-2019 Lima, Perú

E-mail: pierinaqz@ hotmail.com
Date of acceptance: 13-05-2019 DOI: 10.24875/ACME.M19000062
Available online: 02-10-2019 Arch Cardiol Mex (Eng). 2019;89(3):247-248 www.archivoscardiologia.com 2604-7063/C 2019 Instituto Nacional de Cardiología Ignacio Chávez. Published by Permanyer México. This is an open access article under the CC BY-NC-ND license (http://creativecommons.org/licenses/by-nc-nd/4.0/). 

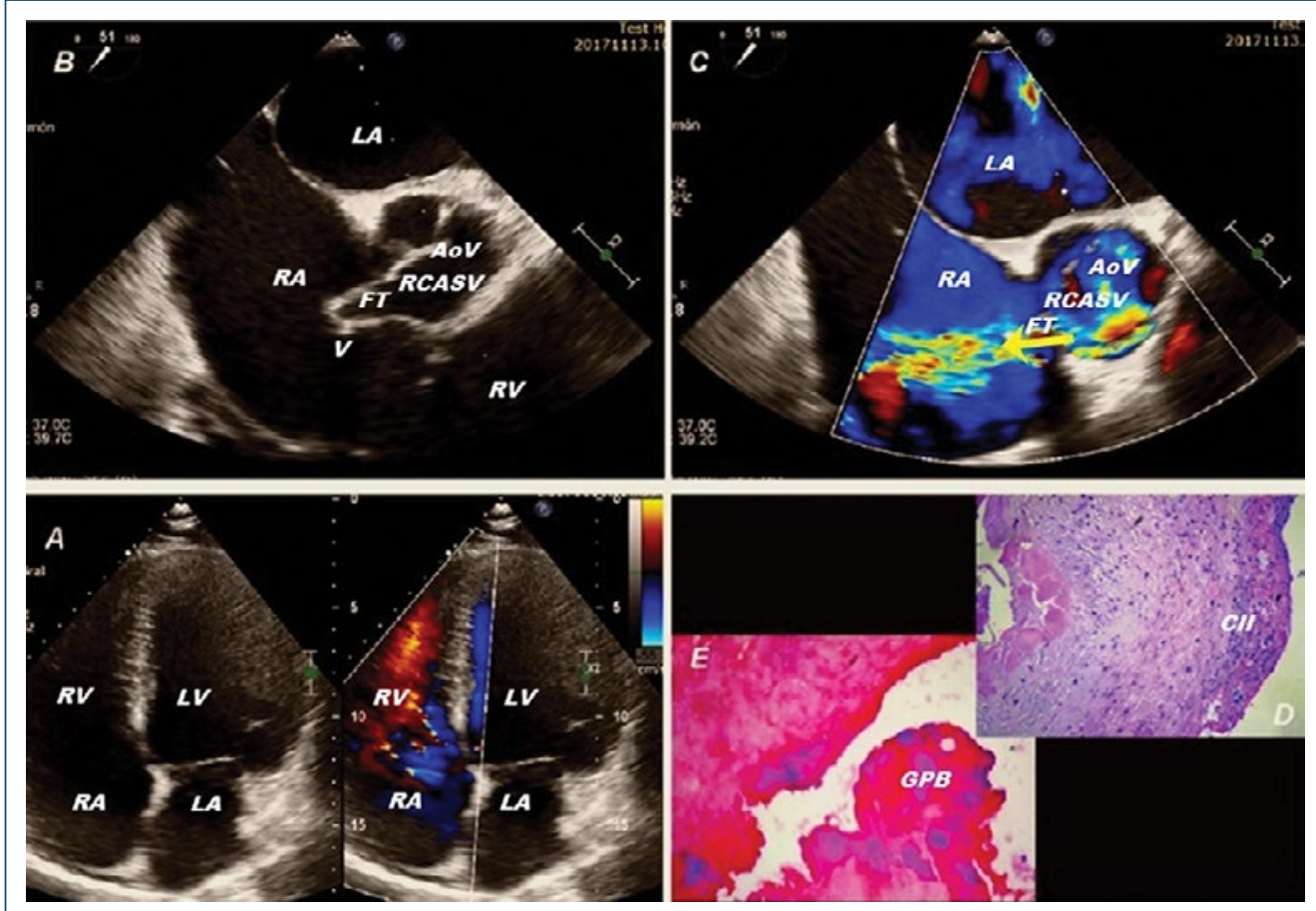

Figure 1. AoV: aortic valve; RCASV: right coronary aortic sinus of Vasalva; RA: right atrium; LA: left atrium; RV: fight ventricle; LV: left ventricle; FT: fistulous tract; V: vegetation; GPB: colonies of Gram-positive bacteria; Arrow (shunt Peftright); CII: chronic inflammatory infiltrate.

\section{Ethical disclosures}

Protection of human and animal subjects. The authors declare that no experiments were performed on humans or animals for this study.

Confidentiality of data. The authors declare that they have followed the protocols of their work center on the publication of patient data.

Right to privacy and informed consent. The authors have obtained the written informed consent of the patients or subjects mentioned in the article. The corresponding author is in possession of document.

\section{References}

1. Habib G, Lancellotti P, Antunes MJ, Bongiorni MG, Casalta JP, Del Zotti $F$, et al 2015 ESC guidelines for the management of infective endocarditis: the task force for the management of infective endocarditis of the European society of cardiology (ESC). Endorsed by: European association for cardio-thoracic surgery (EACTS), the European association of nuclear medicine (EANM). Eur Heart J. 2015 36:3075-128. 